\title{
The Research of Movie Diversification Transmission Plate in the Field of Integrated Media
}

\author{
Yue Wu \\ School Of Communications, Liyi University, Liyi 276001, China \\ paperiset@163.com
}

Keywords: Integrated media, transmission, diversification.

\begin{abstract}
This paper is divided into four parts: The first introduces the film with traditional media such as television, audio-visual new media networks, public media, mobile Internet media smart phones combined condition, that movie diversified spread of the status quo. The second part focuses analyze mufti-platform movie dissemination of results. First we introduced under the new communication environment, audience development of new features. Secondly, through the analysis of national professional movie channels, movie viewing CCTV movie channel data, network, and other authoritative websites demand rate data, and video data to compare, explained the various media platforms showing movies propagation characteristics and, finally, at different audiences Outlook platform shadow preferences. The third part from a public space and time, personal time and space perspective to illustrate the different collective and individual viewing experience choose different channels to reveal the audience viewing demands further corroborated the conclusion of the second part .Based on this, that the trend of making the film multimedia age. Films in various media platforms emitting heat to build up the image of an omnipotent rave era, mufti- media film spread on the surface of each array, in fact, "he扣each other, , , and coexistence. The movie is not just the future under the new wonders of technology to create products, but also pay more attention to inherent expressiveness of the film, to adapt to the movie theaters in addition to entities outside the flow of the living environment of the various media platforms.
\end{abstract}

\section{Introduction}

Multimedia era, the Chinese media market is complex and rapid development. Such an unprecedented all-media environment surrounded us in a lot of media to include mixed media era building outdoor media, outdoor car media, Internet mobile med era, Internet, television and other coexistence and common prosperity Single media audience stickiness decline, the audience diverted by a movie screen, television screens, computer screens, mobile phone screens and other large and small, "curtain", the audience the opportunity to greatly increase the catalyst, the catalyst life time fragmentation rhythm extended [1]. In-depth development of information technology and mobile multimedia technology for the film provides a new channel of communication through television, DVD player or watch movies on the Internet and even into the theater to watch movies more than evident as our movie viewing habits.

Internet has changed the whole pattern of media has changed the rules of information dissemination, attracting a massive audience participation [2]. The new audiovisual media massed spread gradual but also adapt to this trend spread movie started and the "theme" of dissemination activities based on network and phone users' massed. Potential audience network propaganda film, we are trying to rely on a large number of new media viewing of marketing to theater. However, the best marketing is to create a good product, theater face competition for audiences with their multimedia platform, is both an opportunity and a challenge. 


\section{Survey}

Integrated Media. The integrated media which serve as the newly emerging media platform give rise to impressed influence to the audience in daily routine life with it's multimedia information transmission and diversified values, world outlook and esthetics exerting subtle influence to the appreciation of beauty of the audience by the symbolic landscape [3]. This subject study is based on the researching and investigating the influence and affect of the audience transmission plate psychology, measuring the positive and negative impact integrated media takes, discuss and suggest maximizing the value and contribution to today's society.

First, there is undeniable that under the influence of the integrated media the consumerism complex of audience transmission plate increasingly prominent. The impact of the integrated media not only focuses on the inner transmission plate but the value of instant as well. Integrated media provide the huge platform for information transmission with barrier free application and convenient spread channel which eliminates the traditional immutable elitism transmission plate. Therefore the point of transmission plate of everyday fife, transmission plate generalization and secularization which proved to be derivation of the integrated media exerts tremendous impact on the audience transmission plate.

Meanwhile, the "Transmission plate Utopia" has been pushed back with its intensive relationship with the integrated media. It has been treated as the ideal channel to transmit and realize perfectionism. As a result the achievement of real Transmission plate Utopia considered a shoulder heavy responsibility.

Secondly, the audience transmission plate was expressed by the diversified medium dissemination. The most manifest element is the elimination of the loftiness: the focus has moved from the traditional "eternal" beauty to the "instantaneous" which gives sensory stimuli to the audience. The outstanding example for this new transmission plate value such as the fashionable "talent show" and "Gate events" once become the hot topic to today's society. The noticeable point is the product of the integrated media which we called as "Virtual image" machine offered the deeper view of society spectacle next, after long time experience of different media level, the most obvious characteristic of transmission plate is the multidimensional carnival which includes the change from "one-dimension" to "multi-angle" with the thorough subversion of the audience transmission plate.

\section{Multiplex movie communication in the era of Multimedia}

With the development of technology and Internet, the penetration of the mobile phone and web TV continues to grow, and more and more people like watching network video. The very forces that spurred a new type of films and television programs called network drama. Compared with the traditional TV drama, the theme of network drama is closer to the social spots. And the network drama is more and more interesting, the audiences of network drama could take participate in the creation of a network drama. What's more, the network drama has certain characteristics of commercial [4]. The network drama makes the online video industry more and more competitive, and urges the video sites to achieve vertical development. But low cost and quality, the lack of innovation leads to the network drama has low-margin. Smart phone applications are shown in Fig. 1. 


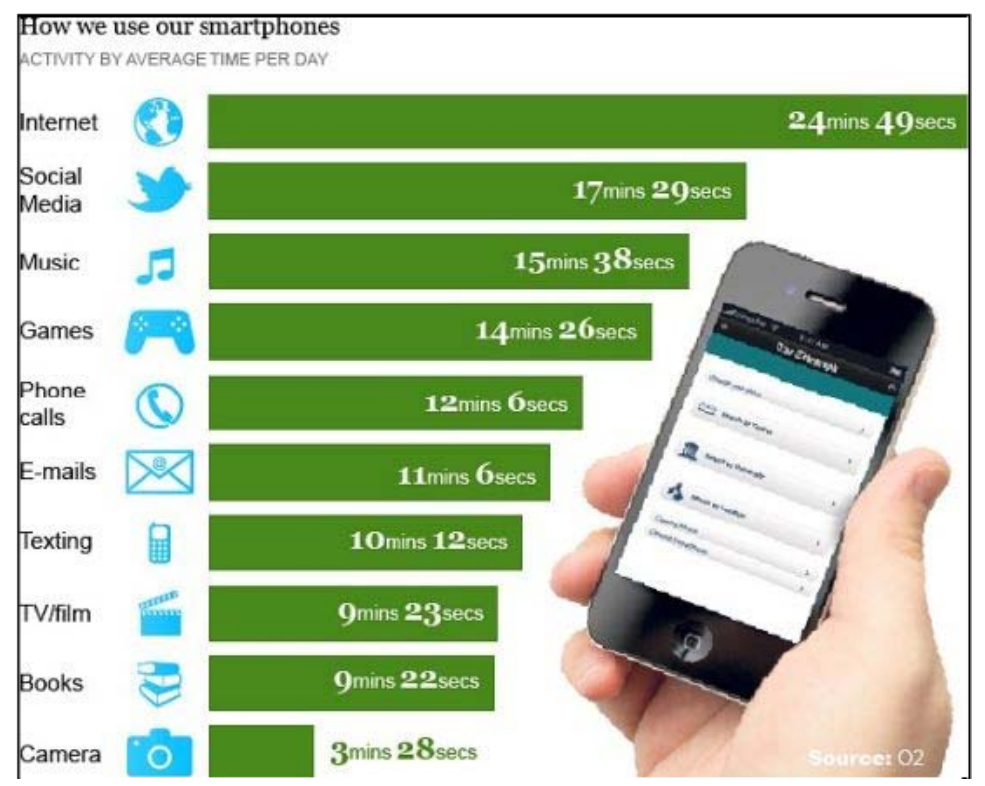

Fig. 1 Smart phone applications

The author analyzed the performance like interactivity, timeliness, participatory, personalized in the film and television production and dissemination, and made a play to the advantages of the new media in the film and television production and dissemination of recommendations. For how to play the new media in the film and television production and dissemination of the advantages of interactivity, the author believes that according to an example of the proposed "To give full play to new media without the constraints of time, widely spread range of advantages, to achieve an open film and television production and dissemination", and "to give full play to the advantage of the strong interaction of new media, new media, select the appropriate production and establish a more open communication platform and channels." For how to play the new media in the film and television production and dissemination of timely advantage, the author believes that according to an example of the proposed "Building more efficient video production and distribution channels" and "should explore the use of new media mainstream sound, the way society is spread energy" and other suggestions; how to take advantage of new media to participate and participatory in the film and television production and dissemination, author "change the way the audience is passive recipients of thinking" and "participatory entertainment" perspectives put forward countermeasures; For how to play the new media in the film and television production and dissemination of personal advantage, the article proposes to focus on personalized recommendations reflect the film and television production and dissemination. Attention economy: an overview, by Alex Iskold is shown in Fig. 2.



Fig. 2 Attention economy: an overview, by Alex Iskold

For outstanding problems exist at this stage, the author believes that "content is too commercialized and vulgarization, there is a tendency deviate from mainstream culture," "inadequate copyright protection, the impact of the creators of enthusiasm", "micro-film profit model the new media environment is not yet clear," "video creators not well aware of the new media's potential for film and television art help "four most prominent issues. 
Development path for film and television production and dissemination of the new media environment, from the perspective of both the future development direction of future development of film and video art communications platform were discussed. The author believes that the future of video communications platform, should seize the "new media," the media, focus on play to its strengths, efforts to catch up with the pace of development to catch up with the times, but new media is not an alternative to traditional media, the two should complement each other, play to their strengths competitive differentiation. Television on the future direction of artistic creation, the author starts from how to meet the meet the individual needs of film and television audience, how to explore new media in the field of film and television production and dissemination of commercial potential, and how to achieve repeated consumption of new media, film and television works, how to mainstream film Institute and Smart TV business together, take the fine development direction were discussed.

In recent years, the state advocate and promote the construction and development of cultural and creative industries, in order to strengthen the national image building in the new period, and meet the growing demand for cultural consumption [5]. As an important part of Chinese cultural and creative industries keep moving, the development of Film and TV art plays an important role in guiding and promoting the development of China's cultural and creative industries. The research of Film and TV art in Micro-communication is to explore the new ideas for the development of Chinese film and TV art in future.

Film and TV art in micro-communication refers to the communication behavior of Film and TV art with the help of micro-media. Micro-media as one of the main media in era of micro-communication, micro media not only has some characteristics of traditional mass media, but also has the mobility, inclusive, interactive, open characteristics of micro-media that it is unique. Both supplement each other and form the force of communication [6]. At the same time, the micro-media and other kinds of media through the mutual integration, to expand its influence, enhance communication efficiency of its own; to maximize the effectiveness of integrated marketing communication. Internet penetration rate is shown in Fig. 3.

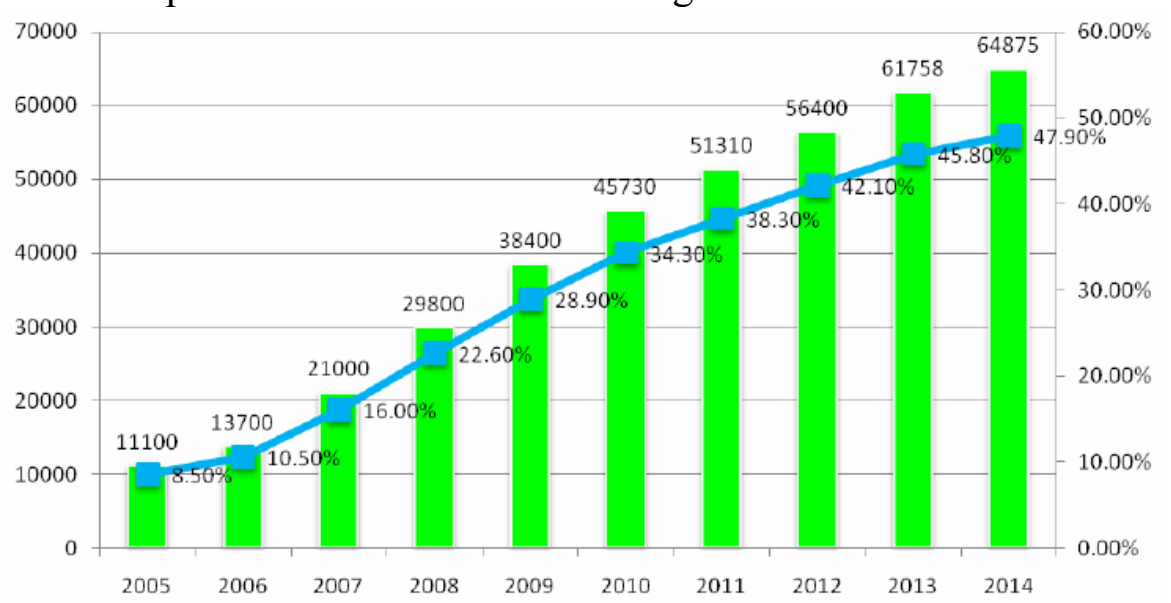

Fig. 3 Internet penetration rate

Relationships between communication and art of film and TV, is really an extension of the relationship between technology and art. Micro propagation by means of film and TV art "magnetization" behavior, improve communication efficiency, strengthen the communication quality, Film and television art in the process of art communication through micro-media, effect of the media, the micro-media becomes art. According to the film and television art and communication, make the micro-communication of film and television art becomes a kind of communication art.

In communication of film and TV art, the new model form developed from the film and television art, is more suitable for the era of communication. The representative is micro-film and micro-television. The rise of micro film and micro TV, broaden the film and television art performance space, enrich the connotation of the subject of film and Television Arts, paved the way for the diversified development of film and television arts. Finally, Accept the dissemination process 
of in Film and TV art, the audience through the contact of the "media text" of film and TV art to feel the spirit of joy, which film and television art bring. The research also according to the needs' level of the audience, communication of film and television art could be divided into acceptance of information, acceptance of culture and acceptance of aesthetics which is three levels. Through the discussion of the film and television art in communication can be seen, that communication of film and TV art spread out a new space for the development of Chinese film and TV art, and points out a new way for the development of film and TV art.

\section{Case analysis}

From the great popularity of "Soldiers Sortie" on the Internet to the network linkage of showing new "Water Margin", Chinese TV dramas have broken the conventional single way of broadcasting, which forms a new pattern of "golden time" to get high audience ratings. Internet and other new media with their own characteristics not only fit the features of TV dramas' spreading, but also gradually change the aesthetic modes and broadcast patterns of TV dramas. New media becomes the second largest channel of TV dramas' spreading and even begins to challenge the status of traditional television stations.

This thesis attempts to macroscopically seize the new media ecology of Chinese TV dramas from the perspective of communication through showing the new media environment built by new media and the social cultural environment; then it will focus on the new broadcast features of Chinese TV dramas in the environment of new media from several important factors of communication: the young culture of the communicative audience, the extension of the communicative content, the innovation of the communicative pattern and development of the promotion, trying to explore the hidden troubles in the spread of TV dramas by new media based on the investigation and analysis of the present situation. which are the lack of artistry and the tangled warfare of finally the thesis will seek the coping strategies and the new trend of development for communication according to the previous three chapters.



Fig. 4 Mobile network economy scale

Mobile network economy scale is shown in Fig. 4. This study shows that new media has influenced the spread of Chinese TV dramas in every aspect and they promote the dissemination of Chinese TV dramas. Chinese TV dramas should make good use of the advantage of new media, grasp the aesthetic anticipation of the audience, integrate the old media, achieve the spread of media linkage and create a harmonious communicative environment to obtain the maximum value of communication. Meanwhile, the thesis helps to form a vision for the future development of Chinese TV dramas by having a clear understanding of the new pattern: Chinese TV dramas need more interactive elements in content based on the features of a new generation of young audiences; Degasify Communication becomes an effective way for Chinese TV dramas to attract the audiences' attention based on the diversification of media channels; and by the upgrade of the promotion, the spreading depth and breadth of Chinese TV dramas has been extended, the marketing space has been expanded, the word of mouth has been escalated, and the spread of brand has gradually been developed. 


\section{Summary}

Last but not least, the real meaning of this research lies in the following three dimensions: the utilitarian of transmission plate satisfaction by the concurrence of "Audience-centered theory", the personalization of the transmission plate trends and how to maximize the positive effect of integrated media. The innovative standpoints in this dissertation prove to the integration of beauty, western literary theory, psychology and communication with social reality and make proper suggestion.

\section{Acknowledgements}

This article is the resuilt of the issue Research on the multimedia platform of Luju in all media era, which belongs to the Important Art Issues of ShangDong 2015(the item number is 1506216)

\section{References}

[1] Spillard C, Pennock S R, Shepherd P R. Absorbing boundary conditions for the modeling of scatterers in parallel-plate transmission media. IEEE Microwave \& Guided Wave Letters, 1995, 5(8):241 - 242.

[2] Cuttner C D, Cotsen S, Paulson Iii H M, et al. Integrated media viewing environment: US, US8683518[P]. 2014.

[3] Boszormenyi I M, Sharma A, Ranjan R Y. Integrated laser cleaning and inspection system for rigid thin film media for magnetic recording application: US, US 6394105 B1[P]. 2002.

[4] Springmuhl Samayoa J E. Integtated Media System And Method: US, WO/2008/155660[P]. 2008.

[5] Zhang X T. The New Concept of Movie Advertising Transmission and Design \& Production in the Internet Age. Journal of Hunan Industry Polytechnic, 2013.

[6] Zhang T. Research of Idioms in the Record of the Transmission of the Lamp Published in the Ching-te Era. Journal of Southwest Agricultural University, 2009. 